\section{Fruit and vegetable seed production and marketing: existing practice and perception of vegetable seed farmers and sellers in Bangladesh}

\section{Mustafiz Shahriar ${ }^{\mathrm{a} *}$, Akira Nakayasu ${ }^{\mathrm{b}}$, Itabashi Mamoru $^{b}$, Masuda Kazuya ${ }^{c}$}

\author{
aThe United Graduate School of Agricultural Science, Ehime \\ University, Tarumi 3-5-7, Matsuyama 790-8566, Japan \\ bFaculty of Agriculture, Ehime University, Tarumi 3-5-7, \\ Matsuyama 790-8566, Japan \\ cFaculty of Agriculture and Marine Science, Kochi University, \\ 200 Otsu, Monobe, Nankoku city, Kochi 783-8502 Japan
}

Received: November 19, 2019 / Accepted: April 22, 2021

\section{Abstract}

Bangladesh has the largest river delta in the world and is known as the basin of South Asia. Accordingly, Bangladesh is naturally fertile, which is the main factor that provides the country with a huge opportunity to produce fruit and vegetable seeds. However, the lack of quality seed production, insufficient seed supply, and lack of seed preservation systems make the seed sector unstable. This research attempts to determine the cause of these problems and identify ways to mitigate them and make a sustainable marketing system. A descriptive research method was applied, based on a survey conducted in Bangladesh in three major seed producing divisions, namely: Dhaka, Chittagong, and Mymensingh. The data were gathered from 40 farmers and 40 retailers \& wholesalers who were chosen at random, and the data was analysed in Microsoft Excel. The objective of the study is to analyze marketing practices of vegetable and fruit seeds, the problems of vegetable and fruit seed distribution, and to propose a method for the sustainable distribution of vegetable and fruit seeds. The results showed a lack of genuine and timely market information, poor institutions and arrangements, and poor marketing infrastructure. These findings are indicative of poor marketing efficiency and thereby suboptimal operation of the seed marketing system. Hence, the results found in this study should help to institute appropriate measures for production, market infrastructure, arrangements, and institutions to improve the inefficient functioning of the seed marketing system.

Keywords: Marketing system; sustainable; structure; conduct; performance; channel; margin; market supply; market demand.

Abbreviations:

MOA : Ministry of Agriculture

\section{Introduction}

Bangladesh has the world's biggest river delta which is known as the South Asian basin (Vriend, 2009). This feature of the country is the main factor that provides a huge opportunity to cultivate fruits and vegetables, along with their seeds. In addition, the sector has enormous potential to boost overall agricultural growth (Negi, 2015).

According to the Ministry of Agriculture, the production and distribution of quality seeds are insufficient in the public sector compared with demand (MOA, 2015). An efficient marketing system plays an important role in sustainable economic development because it stimulates production, helps to avoid unnecessary fluctuation in output and prices, and reduces the cost of production (FAO, 2017). Smartgrowth, long-range planning, cost-saving, R\&D spending, and cost of living are some key concepts in economic sustainability. This is a problem for the sustainable promotion of vegetable and fruit production, and the existing structure and sustainability of seed producers are being questioned (OECD, 2001).

However, the actual state of marketing of vegetable and fruit seeds in Bangladesh has not been fully clarified. In Bangladesh, the seed marketing system follows the channel: company/farmer $\rightarrow$ wholesaler $\rightarrow$ retailer $\rightarrow$ seed user. Current seed distribution systems are incapable of ensuring consistent supply and set prices for vegetable and fruit seeds. Many countries' experience indicates that without an effective marketing system policy, agricultural growth would be limited in its ability to stimulate production and contribute to price stability (Negasi, 2016). As a result, the task is to perform a survey of retailers and farmers in order to determine the current state of vegetable and fruit seed marketing, as well as to determine the distribution route for seeds and the issues that may arise. Simultaneously, we suggest policy solutions to address these issues. One of the most widely cited weaknesses of local seed production activities is a lack of market viability and sustainability (Tripp, 200o).

*Corresponding Author

Tel.: +8180-7743-7153;

E-mail: shahriarmustafizudoy@gmail.com 
Hence, the objectives of this study were to identify a) the marketing practices of vegetable and fruit seeds, b) the problems relating to vegetable and fruit seed distribution, and c) to propose a system for the distribution of vegetable and fruit seeds in a sustainable manner.

Table 1 Major varieties of vegetable and fruit seeds production locations in Bangladesh

\begin{tabular}{|c|c|c|c|}
\hline Division & $\begin{array}{c}\text { Vegetable seed } \\
\text { variety }\end{array}$ & $\begin{array}{c}\text { Fruit seed } \\
\text { variety }\end{array}$ & District \\
\hline $\begin{array}{l}\text { Dhaka } \\
\text { (Central } \\
\text { region) }\end{array}$ & $\begin{array}{l}\text { Lettuce, cabbage, } \\
\text { broccoli, celery, } \\
\text { tomato, bottle } \\
\text { gourd, okra, } \\
\text { onion, cucumber, } \\
\text { red amaranth, } \\
\text { spinach cress, } \\
\text { snake gourd, } \\
\text { drumstick, green } \\
\text { papaya, luffa, } \\
\text { pumpkin, } \\
\text { cauliflower, } \\
\text { radish, hot pepper }\end{array}$ & $\begin{array}{l}\text { Papaya, } \\
\text { watermelo } \\
\text { n, musk } \\
\text { melon, } \\
\text { strawberry }\end{array}$ & $\begin{array}{l}\text { Dhaka, } \\
\text { Gazipur, } \\
\text { Manikgonj, } \\
\text { Tangail } \\
\text { Mymensingh, } \\
\text { Sherpur, } \\
\text { Jamalpur, } \\
\text { Rajbari, } \\
\text { Faridpur }\end{array}$ \\
\hline $\begin{array}{l}\text { Chittagong } \\
\text { (South east } \\
\text { region) }\end{array}$ & $\begin{array}{l}\text { Lettuce, cabbage, } \\
\text { broccoli, tomato, } \\
\text { bottle gourd, okra, } \\
\text { onion, cucumber, } \\
\text { red amaranth, } \\
\text { snake gourd, luffa, } \\
\text { pumpkin, } \\
\text { cauliflower, } \\
\text { radish, hot pepper }\end{array}$ & $\begin{array}{l}\text { Watermelo } \\
\mathrm{n} \text {, } \\
\text { muskmelon }\end{array}$ & $\begin{array}{l}\text { Comilla, } \\
\text { Chittagong, } \\
\text { Cox's Bazar, } \\
\text { Feni }\end{array}$ \\
\hline $\begin{array}{l}\text { Mymensin } \\
\text { gh } \\
\text { (North } \\
\text { region) }\end{array}$ & $\begin{array}{l}\text { Lettuce, cabbage, } \\
\text { broccoli, celery, } \\
\text { tomato, bottle } \\
\text { gourd, okra, } \\
\text { onion, cucumber, } \\
\text { red amaranth, } \\
\text { spinach cress, } \\
\text { snake gourd, } \\
\text { drumstick }\end{array}$ & $\begin{array}{l}\text { Papaya, } \\
\text { watermelo } \\
\text { n, } \\
\text { muskmelon }\end{array}$ & $\begin{array}{l}\text { Jamalpur, } \\
\text { Mymensingh, } \\
\text { Netrokona, } \\
\text { Sherpur }\end{array}$ \\
\hline
\end{tabular}

\section{Materials and Methods}

\subsection{Data Collection}

The information was gathered in 2017 during an in-depth interview. In each case of vegetable and fruit seed farming, 40 small farmers and 40 small retailers and wholesalers were chosen at random. They were interviewed using a structured questionnaire for data collection. The secondary data were collected from different sources such as stakeholders, line agencies, and government organizations of Bangladesh, NGOs, and INGOs. To verify the data, a questionnaire was created based on respondents' personal and socioeconomic characteristics, such as age, educational level, land ownership, vegetable and fruit seed variety, annual income, and so on.

\subsection{Locale}

The field survey was conducted in the farming communities in three of Bangladesh's eight divisions based on major seedproducing areas: Dhaka in central Bangladesh as the capital city, Chittagong the second major city, and Mymensingh.

\subsection{Fruit and vegetable seed varieties}

The following are lists of available vegetable and fruit seeds, as well as the districts where they are grown (Table 1 ). We can also get a picture of the most commonly grown vegetables and fruit seeds in Bangladesh's three divisions.

\subsection{Method of analysis}

A descriptive research method was used for this study. The marketing system of the fruit and vegetable seed sector was described, and identification of the issues affecting the marketing system was undertaken. The literature was closely studied and the factors influencing the marketing system of Bangladesh's fruit and vegetable seed sector were explained. The principal method of data collection was in-depth interviews of the farmers, and retailers \& wholesalers. The links between the components of seed market system practice and performance were illustrated on the basis of these interviews. The collected data were tabulated, crosstabulated, summarized, and analyzed using MS Excel software. The data collected from the seed farmers and retailers \& wholesalers were tabulated and analyzed using simple statistical tools and techniques such as frequency and percentages. To validate the data, a simple statistical method was used and the results are expressed as mean $\pm \mathrm{SE}$.

\section{Results and discussion}

\subsection{Vegetable and fruit seed retailers \& wholesalers}

\section{Additional expenses after buying vegetable \& fruits seeds}

The results show that $50 \%$ of the vegetable seed retailers \& wholesalers have additional expenses for transportation in wholesaling, whereas $25 \%$ of the respondents have additional expenses for transportation in retailing (Fig. 1). For cleaning and grading and seed treatment, $45 \%$ and $47.5 \%$ of the respondents, respectively, have additional expenses in wholesaling, while $40 \%$ and $25 \%$ of the respondents, respectively, have additional expenses in retailing (Fig. 1). For packaging and promotion, $37.5 \%$ and $17.5 \%$ of the respondents in wholesaling, and $45 \%$ and $37.5 \%$ of the respondents in retailing, have additional expenses (Fig. 1). For seed-producing farms, the winnowing charge was the highest cost item, followed by transportation, bagging, and labor (Ray, 2001). 


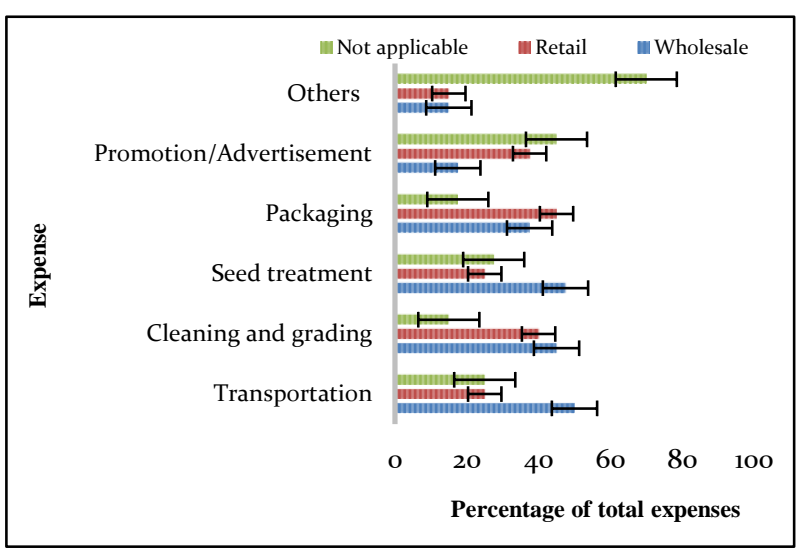

Figure 1 Additional expenses after buying vegetable seeds from retailers \& wholesalers.

The study further shows that $75 \%$ of the fruit seed retailers \& wholesalers have additional expenses for transportation in wholesaling, whereas $25 \%$ of the respondents have additional expenses for transportation in retailing (Fig. 2). For cleaning and grading and seed treatment, 55 and $67.5 \%$ of the respondents, respectively, have additional expenses in wholesaling, while 37.5 and $27.5 \%$ of the respondents, respectively, have additional expenses in retailing (Fig. 2). For packaging and promotion, 67.5 and $50 \%$ of the respondents in wholesaling, and 30 and $37.5 \%$ of the respondents in retailing, have additional expenses (Fig. 2). The transportation facilities in the study area play an important role in every activity of the vegetable and fruit farmers to make a sustainable long-run seed distribution system. Transportation cost is relatively higher for fruit seeds compared to vegetable seeds.

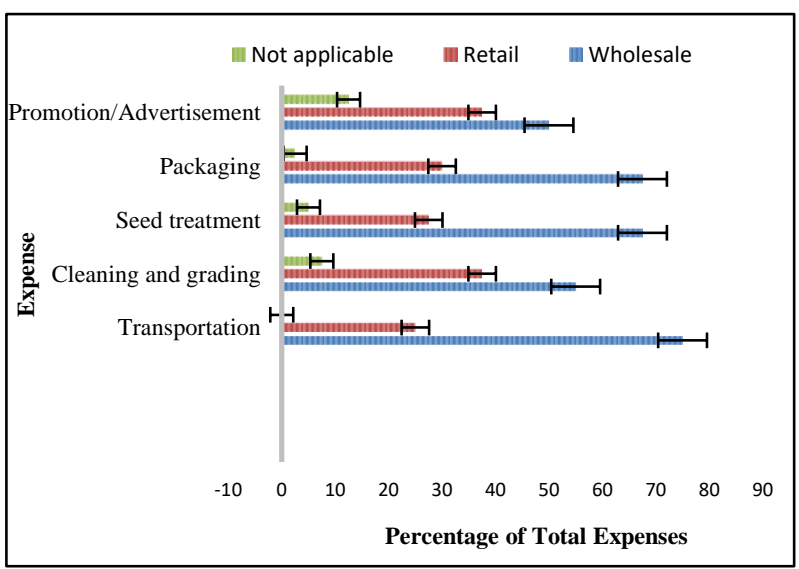

Figure 2 Additional expenses after buying fruits seeds from retailers \& wholesalers.

\section{Demand and supply of vegetable \& fruit seeds}

Demand and supply of vegetable \& fruit seeds were categorized on the basis of seed price and types. It was found that in the three divisions, $40 \%$ of the respondents have a high demand for vegetable seeds, $35 \%$ of the respondents have a medium demand, and $25 \%$ have a low demand (Fig. 3). Further, supply was high for $35 \%$ of the respondents, medium for $42.5 \%$, and low for $22.5 \%$ (Fig. 3). The gap between local production and demand for seed amounts to nearly $87 \%$. To overcome the scarcity of domestic seed supply, imported seeds play a significant role in Bangladesh's seed industry (Hazra, 2008). From these data, it is clear that the government is downplaying the importance of costsaving which is a barrier to a sustainable seed distribution system. Transportation is a crucial component of achieving sustainability and is becoming a touchstone for development towards the future. (Marchese 2015).

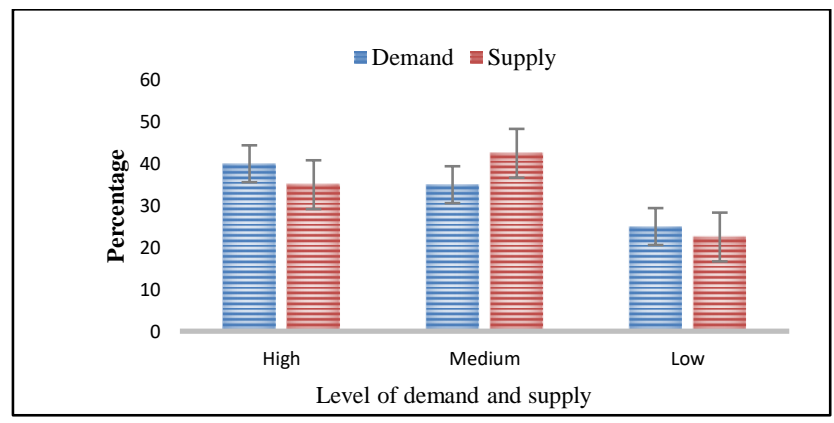

Figure 3 Demand and supply of vegetable seeds based on price and types.

It was found that in the three divisions, $45 \%$ of the respondents have a high demand for fruit seeds, $42.5 \%$ of the respondents have a medium demand, and $12.5 \%$ have a low demand (Fig. 4). Further, supply was high for $40 \%$ of the respondents, medium for $45 \%$, and low for $15 \%$ (Fig. 4). This indicates that seed demand is higher than the supply in all cases, which implies sufficient ongoing demand on which to create a sustainable seed distribution system. In the case of vegetable seeds, the demand is more than the supply, while in the case of fruit seeds there is supply similar to the demand.

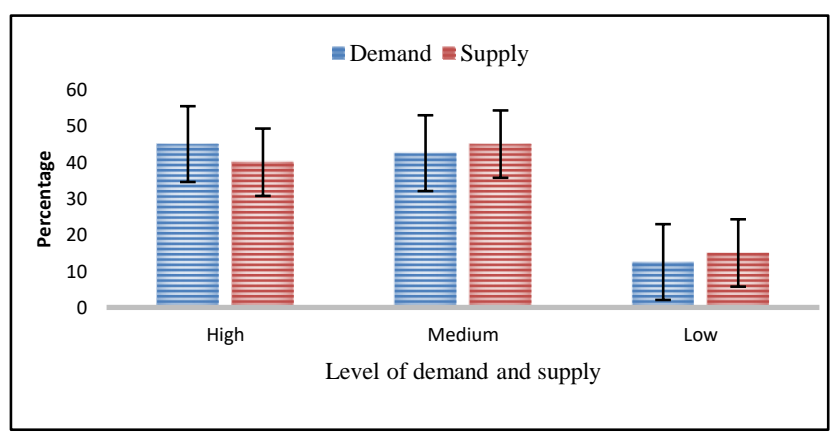

Figure 4 Demand and supply of fruit seeds based on price and types. 
Average vegetable and fruit seeds selling in the year 2017

The data show that in the year 2017 , on average, $73 \%$ of the total seeds sold was through wholesaling. The remaining $27 \%$ on average was through retailing (Fig. 5). The majority of vegetable seed retailers rely on wholesalers, which means that only one-third of retailers are able to access producers, resulting in a reliance on the wholesale market.

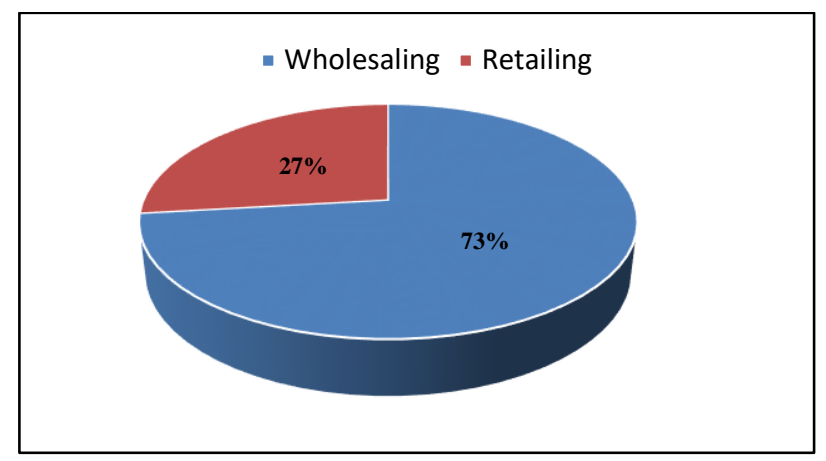

Figure $\mathbf{5}$ The average quantity of vegetable seed sold in the year 2017.

According to the data, in 2017, wholesaling accounted for $66 \%$ of total fruit seed sales, while retailing accounted for the remaining $34 \%$. (Fig. 6). The majority of retailers rely on wholesalers, which means that only one-third of retailers are able to access producers, resulting in a reliance on the wholesale market. As a consequence of relying on this intermediary, the cost of living will grow, creating an obstacle to a sustainable seed distribution system. In both wholesale and retail, the total quantity of fruit seed sold is $7 \%$ greater than that of vegetable seed.

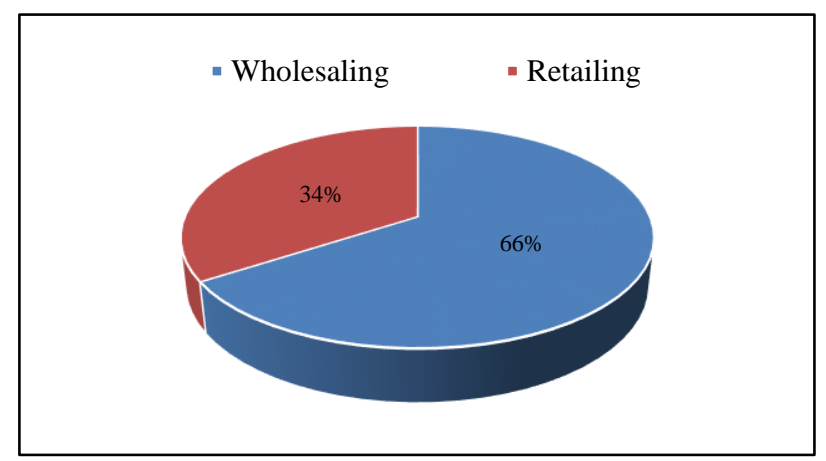

Figure 6 The average quantity of fruit seeds sold in 2017

\section{Suggestions for vegetable and fruit seed retailing and wholesaling}

Among the suggestions provided by the retailers \& wholesalers, $27.5 \%$ stated that seed price should be properly monitored by the government, which is very important to obtain a consistent supply of seeds and to ensure farmers do not hamper sustainable distribution if the price is monitored all over the country (Fig. 7). The retailers \& wholesalers $(12.5 \%)$ suggested that there are no government subsidies to stimulate the seed sector, which makes the whole industry sluggish (Fig. 7). Field inspections must be performed in a timely and thorough manner, and the seed certification agency must be strengthened (Shaheb, 2015).

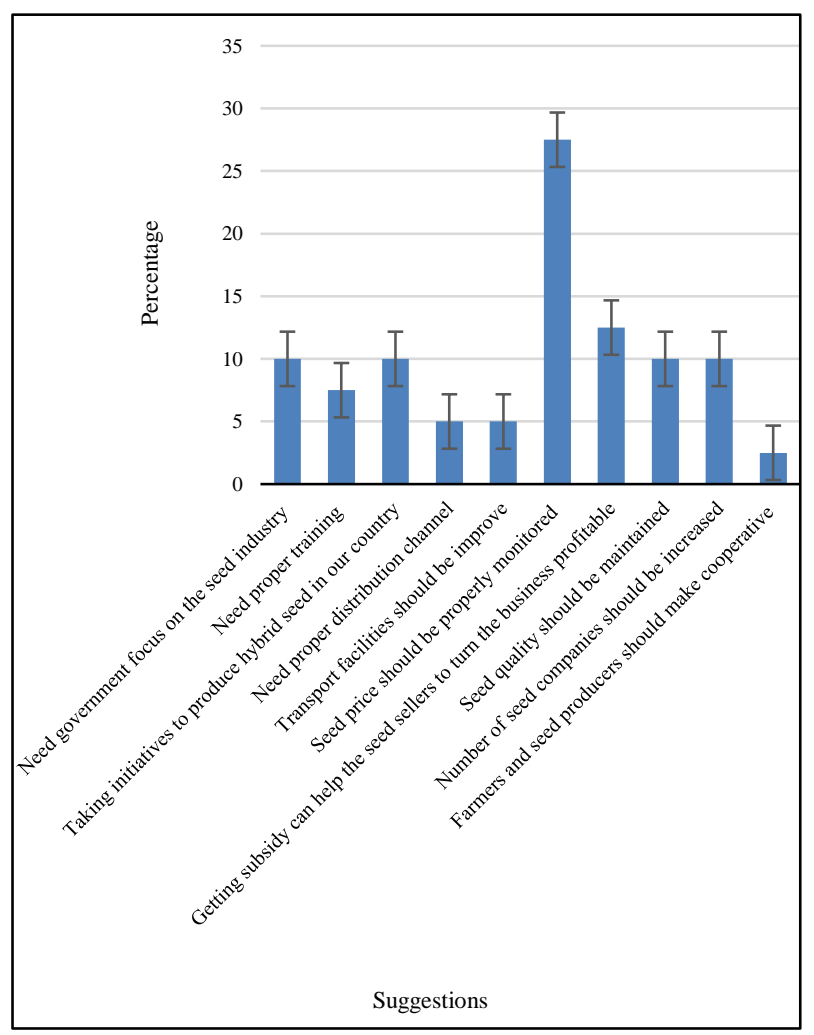

Figure 7 Suggestions for vegetable seed retailing and wholesaling.

Most of the retailers and wholesalers enforce to maintain monitoring system of the vegetable seed quality (Fig. 8). Since there is no government criterion that can guarantee the quality of fruit seeds. Second, the government's seed price monitoring system is an important part of ensuring seed quality (Fig. 8). On the other hand, the few seed companies are doing monopoly business but also contribute to the R\&D sector. So, the competition is not increasing. Retailers and wholesalers want more companies to enter the fruit seed sector. In both vegetable and fruit seeds, price monitoring is the main issue but seed quality in the fruit seed also considered. 


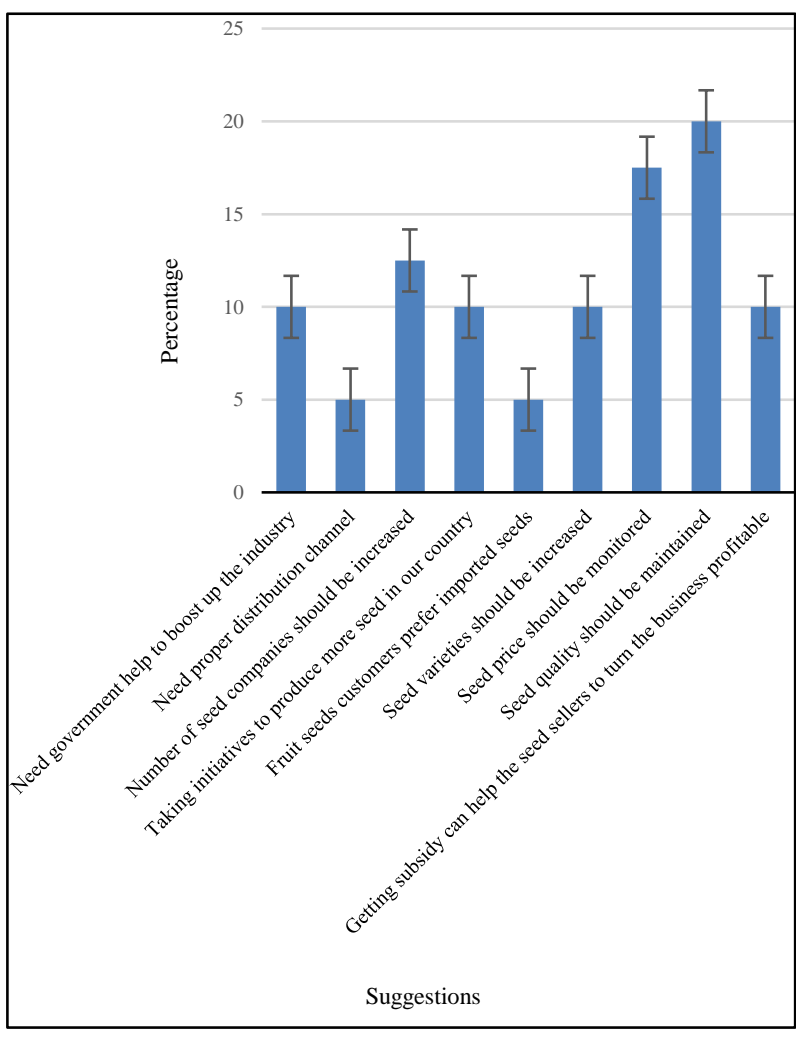

Figure 8 Suggestions for fruit seed retailing and wholesaling.

\subsection{Vegetable and fruit seed farmers}

\section{Cropping patterns of the vegetable and fruit seed farmers}

The vegetable seed farmers usually employed a mixed cropping pattern (Fig. 9). Mixed cropping refers to a method of cropping in which two or more crops are grown simultaneously on the same piece of land. It means most of the producers try to use space effectively, which increases the intensity of cropping and produces vegetable seeds in a sustainable manner.

Fruit seed farmers also use a mixed cropping technique. (Fig. 10). The majority of farmers aim to make efficient use of space in order to generate more planting materials at a lower cost. From this, we can deduce that the practice of sustainability has started in seed farming, although it is not noticeable in the seed distribution system. The vegetable and fruit seed farmers not only followed the mixed cropping pattern but also applied intercropping, crop rotation, mixed farming, ratooning, sole cropping, and monoculture. From this scenario, we can see that farmers also produce vegetable and fruit seeds in other patterns.

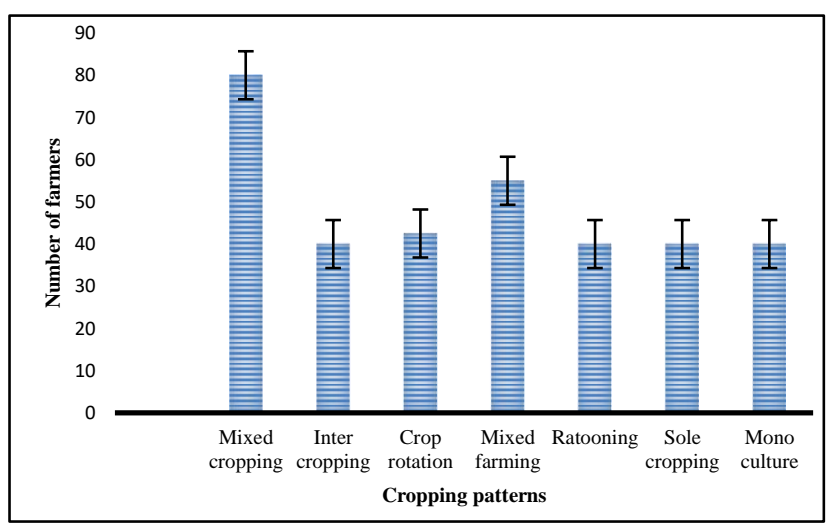

Figure 9 Cropping patterns followed by vegetable seed farmers

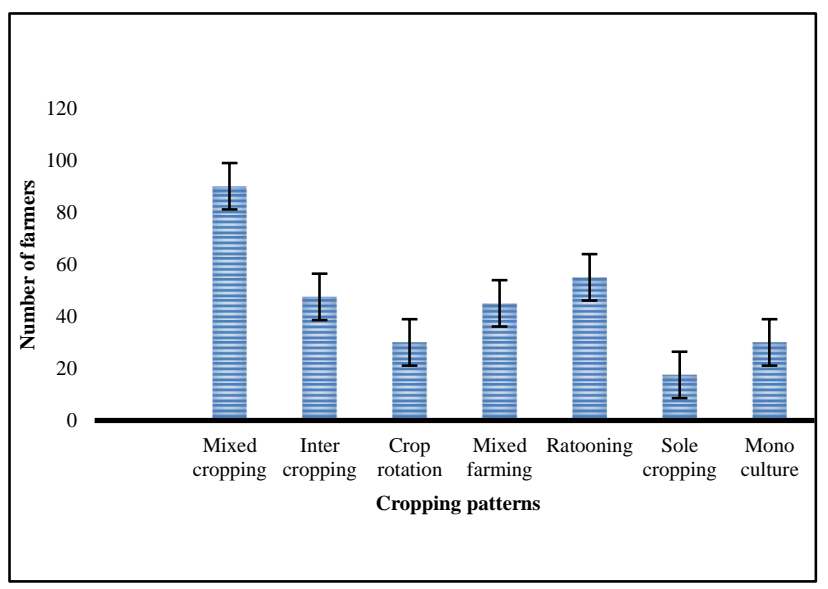

Figure 10 Cropping patterns followed by fruit seed farmers.

\section{Price determination of vegetable and fruit seeds}

Vegetable seed farmers mostly set their price with the different types of channels through negotiation (Fig. 11), as a result, the price of seeds could not be controlled by the government. Therefore, the seed producers determine their price depending on different factors, and almost everyone tries to sell by bargaining. Farmers don't care who buys their seeds, which interferes with long-term planning and leads to an unsustainable seed distribution system. 


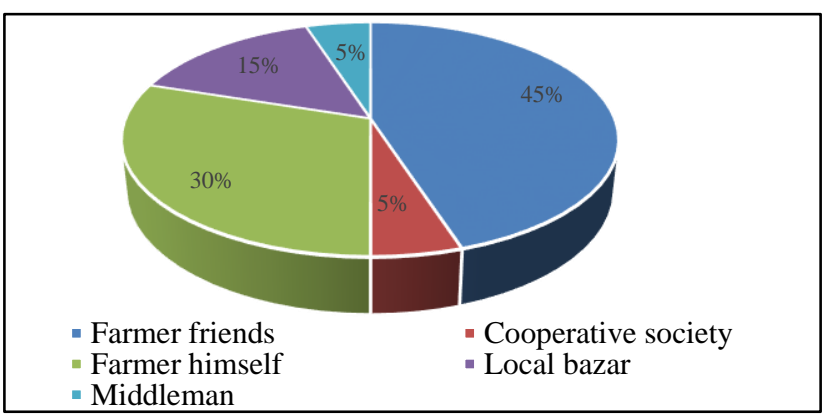

Figure 11 Price determination of vegetable seed through different channels.

Fruit seed farmers also mostly determine the seed price with different channels through negotiation (Fig. 12). Since the price of fruit seeds varies from place to place, such as farmer's friends, cooperative society, buyers, local bazaar, it cannot accelerate a sustainable seed distribution system. For price determination, the farmer themselves and their friends play a vital role in vegetable seed price whereas middlemen are more prominent in fruit seed pricing.

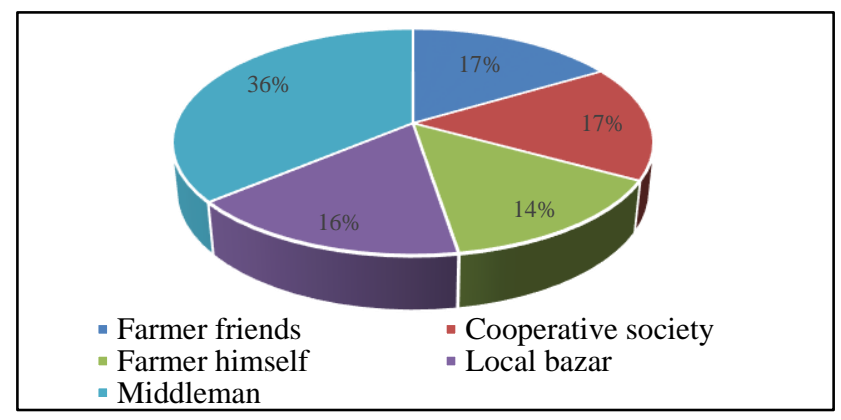

Figure 12 Price determination of fruit seed through different channels.

\section{Profit or loss of vegetable and fruit seeds}

The profit or loss margin of vegetable seeds are presented in Table 2. The survey data reveals that only tomato and cucumber seed production was profitable in the year of 2017. The tomato seed production profit margin was remarkable, but for cucumber, the profit margin was less. Wax gourd, bottle gourd, and snake gourd seed production resulted in significant losses for the farmers, especially bottle gourd. This issue is contradictory with the demand and supply situation described in Figure 3, where demand is high but most of the vegetable seeds are making losses. But the reason is clear from Table 4 which shows that seed price is fluctuating seasonally and with negotiating strength; indicating unsustainable practices in the seed marketing system. Sustainable marketing is built on the principles of equal pricing, which represents long-term success (Iacob, 2010).
Table 2 Profit or loss margin of five selected vegetable seeds

\begin{tabular}{lccc}
\hline $\begin{array}{l}\text { Vegetables } \\
\text { name }\end{array}$ & $\begin{array}{c}\text { Production } \\
\text { cost }\end{array}$ & $\begin{array}{c}\text { Selling } \\
\text { price }\end{array}$ & $\begin{array}{c}\text { Net profit } \\
\text { or loss }\end{array}$ \\
\hline Tomato & 6062.12 & 10000 & 3937.88 \\
Wax gourd & 10382 & 6500 & $(3882)$ \\
Bottle gourd & 14669 & 4700 & $(9969)$ \\
Cucumber & 11040 & 12500 & 1460 \\
Snake gourd & 13618.5 & 8000 & $(5618.5)$ \\
\hline \multicolumn{4}{c}{ Source: Field survey (February 11, 2017) }
\end{tabular}

In the fruit seed market, farmers lost money on watermelon, musk melon, and strawberry seeds per $\mathrm{kg}$, according to the results. Only the papaya seed producers made money, and this was only a small profit (Table 3 ). From this, it can be assumed that the farmers are always facing losses due to a lack of sustainable marketing systems in Bangladesh. Although there is a loss in the production of some vegetable and fruit seeds, this loss is offset by the overall production dividend.

Table 3 Profit or loss margin of four selected fruit seeds

\begin{tabular}{lccc}
\hline Fruit crop & $\begin{array}{c}\text { Production } \\
\text { cost (BDT) }\end{array}$ & $\begin{array}{c}\text { Selling price } \\
\text { (BDT) }\end{array}$ & $\begin{array}{c}\text { Net profit or } \\
\text { loss (BDT) }\end{array}$ \\
\hline Watermelon & 9372.45 & 8231 & $(1141.45)$ \\
Musk melon & 8987.87 & 7720 & $(1267.87)$ \\
Papaya & 6078.72 & 6500 & 421.28 \\
Strawberry & 12740.11 & 9666 & $(3074.11)$ \\
\hline \multicolumn{4}{c}{ Source: Field survey (February 11, 2017) }
\end{tabular}

The data reveal that seed price dependence on seasonality, and bargaining power is also a vital issue that affects the price of vegetable seeds (Table 4). To make economic sustainability in the seed sector it is mandatory to focus on seasonality and bargaining power which can control the price of the seeds.

Table 4 Factors affecting the price of seeds

\begin{tabular}{lc}
\hline Factors & Percentages \\
\hline Seasonality & 23 \\
Availability of the product & 13 \\
Bargaining/negotiating strength & 20 \\
Availability of processing unit in the area & 13 \\
Availability of markets & 12 \\
Road/transport system & 8 \\
Market information & 11 \\
\hline
\end{tabular}

\section{Farmers' satisfaction of vegetable and fruit seed selling price}

The data further reveal that $45 \%$ of the vegetable seed producers were not satisfied with the price they obtained through selling their seeds (Fig. 13), which means in comparison to other seed production, such as cereal, farmers receive reasonable prices for vegetable seed. Seed production of hybrids is more profitable and is popular in crops like rice, 
maize (composites), vegetables, flowers, sunflower, etc. (Tomar, 2011).

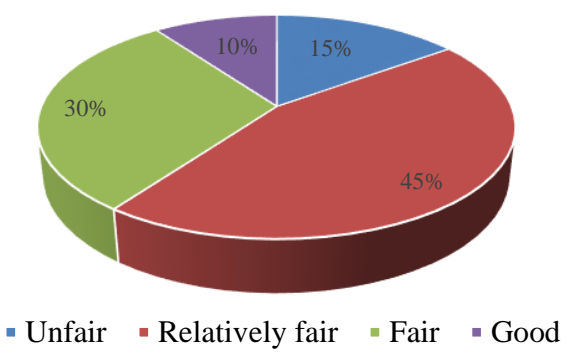

Figure 13 Farmers' satisfaction of vegetable seed selling price.

The data reveal that $50 \%$ of the fruit seed producers considered the price they obtained for their seeds was relatively fair (Fig. 14. Farmers are getting relatively fair prices for fruit seed production compared to other seed production such as grain and flower seeds. From the data, it is clear that farmers are not completely satisfied by selling the vegetable and fruit seeds. So, to obtain a fairer price farmers should grow hybrid seeds along with local seeds.

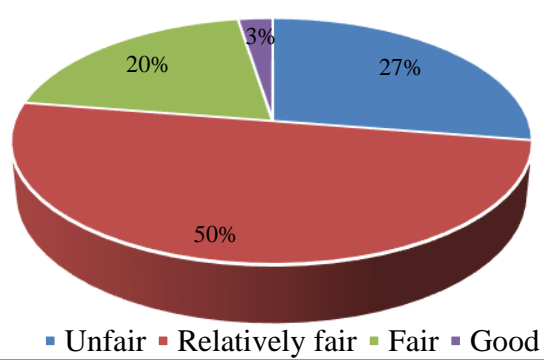

Figure 14 Farmers' satisfaction of fruit seed selling price

\section{Components to influence the price of vegetable and fruit seeds}

In determining the price of vegetable seeds, collectors play a vital role (Table 5) because collectors or traders collect the seeds from farmers and sell them in the retail market. Therefore, by bringing the seeds from remote areas and selling them in a high-demand market, traders can gain more profit than the seed farmers. Obviously, the economic imbalance becomes an obstacle to sustainable development.
Table 5 Major components in determining the price of seeds

\begin{tabular}{lc}
\hline Major players & Percentage \\
\hline Collectors & 87.2 \\
Cooperative & 5 \\
Government body & 5 \\
Others & 2.5 \\
\hline Total & $\mathbf{1 0 0}$ \\
\hline
\end{tabular}

Collectors collect seeds from farmers and sell them in the retail market, so they play an important role in deciding the price of fruit seeds (Table 6). As a result, the economic equilibrium is disturbed, which becomes a barrier to sustainable seed distribution system. Collectors play an active role for determining the price of vegetable and fruit seeds.

Table 6 Major players in determining the price of seeds

\begin{tabular}{lr}
\hline Major player & Percentage \\
\hline Collectors & 82.5 \\
Cooperative & 2.5 \\
Government body & 12.5 \\
Exporters & 0 \\
Other & 2.5 \\
\hline Total & $\mathbf{1 0 0}$ \\
\hline
\end{tabular}

\section{Localization and types of vegetable and fruit seed buyers}

The wholesalers are the biggest buyer of vegetable seeds. The data show that $\mathbf{2 7 . 1} \%$ of seeds are purchased by wholesalers, but retailers (23.2\%) and private companies (22.4\%) also buy a large volume of vegetable seeds (Fig. 15). Most of the buyers (retailers, private companies, cooperatives, government institutes, and others) buy $72.9 \%$ vegetable seeds from the local market as compared to wholesalers $27.1 \%$ from all over the country. From the findings, it reveals that most vegetable seeds are sold in the local market.

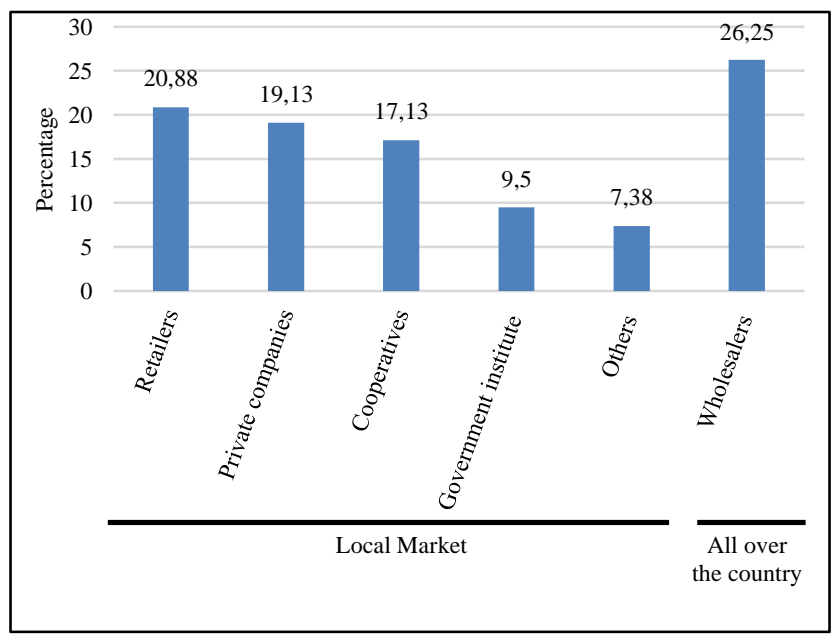

Figure 15 Localization and types of vegetable seed buyer 
The data show that $\mathbf{2 6 . 2 5 \%}$ of fruit seeds are bought by a wholesaler from all over the country, where the majority of fruit seeds $(73.75 \%)$ are bought from the local market. In the local market, the buyers are retailers, private companies, cooperatives, government institutes, and others. It is also observed that fruit seeds are more widely sold in the local market like vegetable seeds.

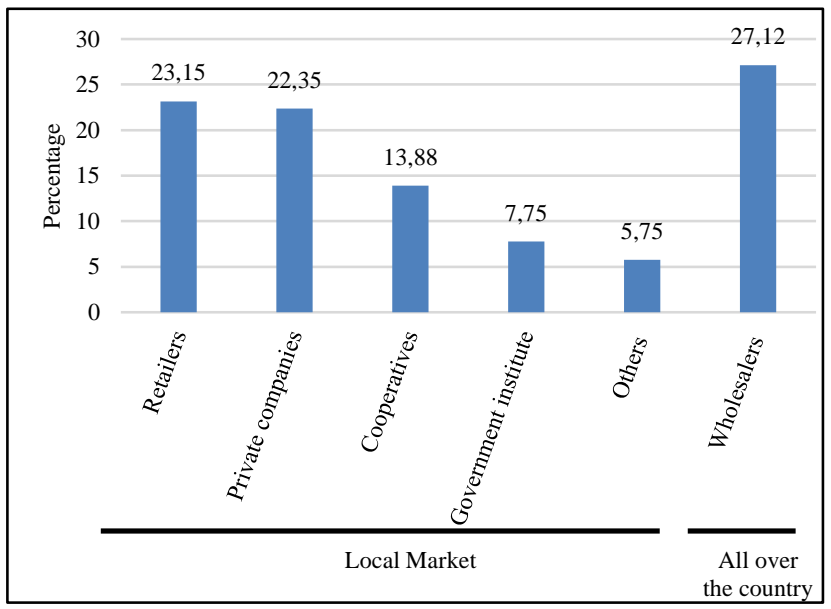

Figure 16 Localization and types of fruit seed buyer

\section{Sources of technical services and marketing information for vegetable and fruit seed}

From the data, technical services for vegetable seed $(<10 \%)$ are provided by government organizations rather than private organizations and NGOs, but marketing services (< $5 \%$ ) provided by all organizations mentioned in the study (Fig. 17). Both technical and marketing services (> 25\%) are provided by all of the organizations for the vegetable seed. From the findings, government should take initiative to increase the services of all of the organizations (BADC, BARC, cooperatives, NGOs, and INGOs) to make a sustainable marketing system for the vegetable seed. Availability of the vegetable seed mostly dependent on the local market ( $>27 \%$ ) whereas the imported (outside) seeds are $<12 \%$. On the other hand, the timely availability of vegetable seeds (regular basis) is $>9 \%$ as compared to irregular basis up to $32 \%$.

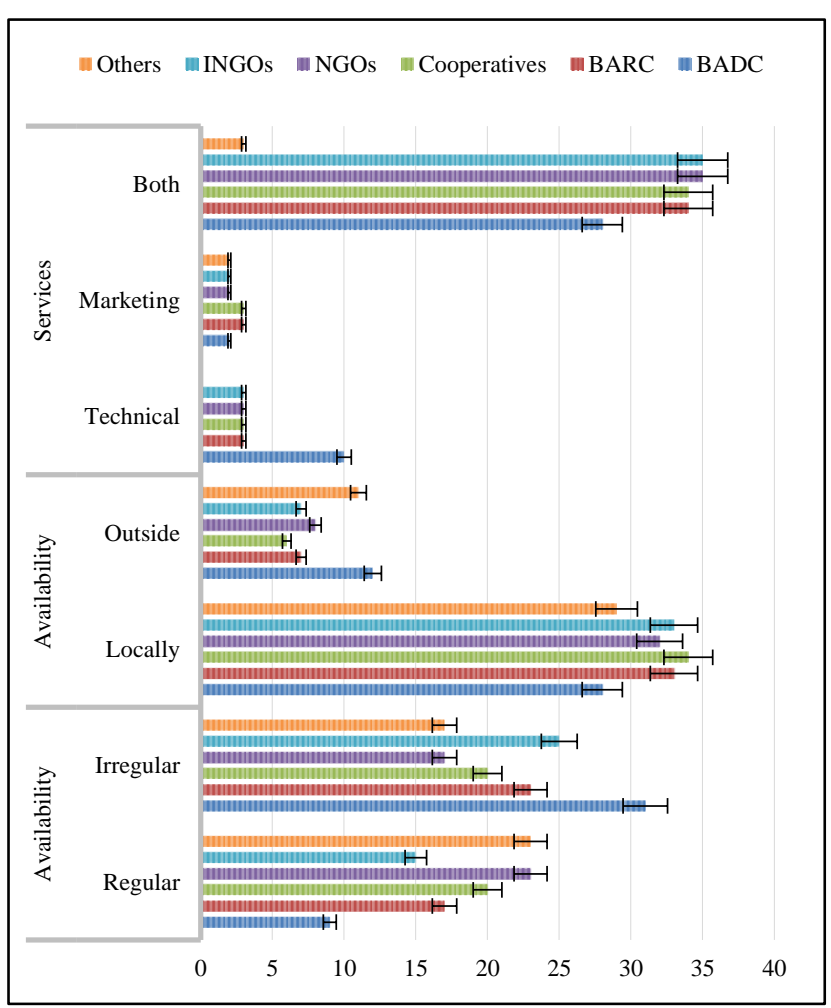

Figure 17 Sources of technical services and marketing information for vegetable seed.

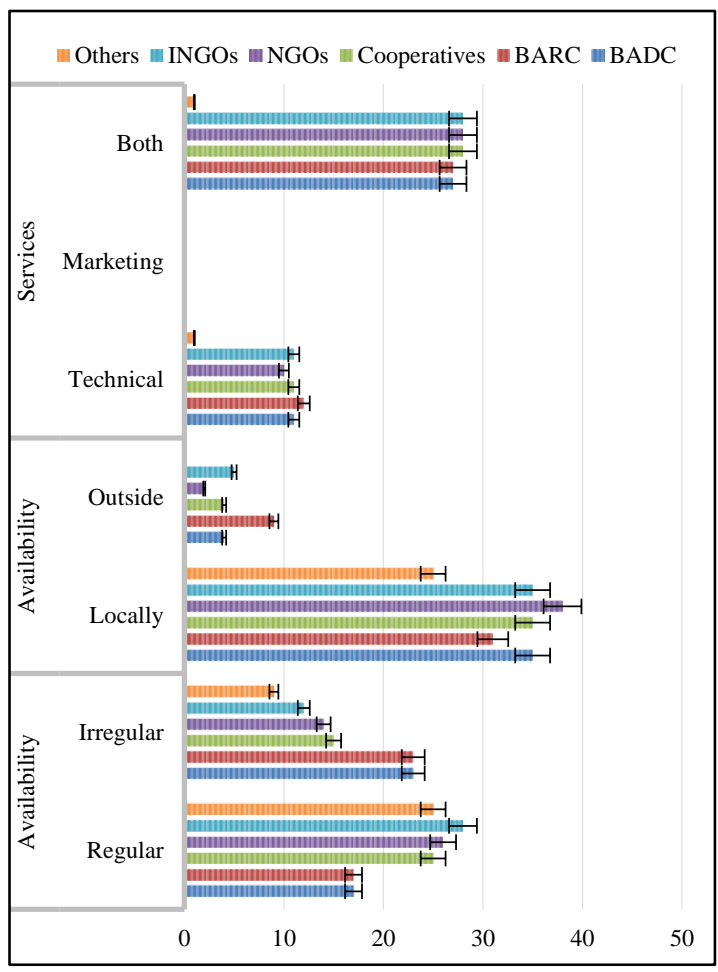

Figure 18 Sources of technical services and marketing information for fruit seed 


\section{Constraints of vegetable and fruit seed farming}

The data (Field survey, February 2017) show there are two major constraints that hamper vegetable seed farming. The first is technical knowledge and a support system for seeds, and the second is seed processing units (Table 7). These constraints mean, that to be sustainable, seed farmers' need proper training, especially technical training, and help from the government so that they can invest more in seed processing procedures. The new vegetable seed farmers face many problems like inadequate government policies for supporting seed processing and marketing groups (Luthfa, 2004).

Table 7 Major constraints of vegetable seed farming.

\begin{tabular}{|c|c|c|c|c|}
\hline Serial No. & Major constraint & High & Medium & $\overline{\text { Low }}$ \\
\hline 1. & $\begin{array}{l}\text { Availability of planting } \\
\text { materials }\end{array}$ & 3 & 29 & 8 \\
\hline 2. & $\begin{array}{l}\text { Quality of planting } \\
\text { materials and inputs }\end{array}$ & 4 & 33 & 3 \\
\hline 3. & $\begin{array}{l}\text { Technical knowledge } \\
\text { and support services }\end{array}$ & 11 & 23 & 6 \\
\hline \multirow[t]{5}{*}{4.} & $\begin{array}{l}\text { Supporting } \\
\text { infrastructure }\end{array}$ & & & \\
\hline & Seed processing units & 11 & 22 & 7 \\
\hline & Road and transport & 4 & 27 & 9 \\
\hline & Collection centre & 4 & 31 & 7 \\
\hline & Credit facilities & 6 & 24 & 10 \\
\hline v. & Land availability & 7 & 26 & 7 \\
\hline 5. & $\begin{array}{l}\text { Information on price } \\
\text { and market }\end{array}$ & 9 & 24 & 7 \\
\hline 6. & $\begin{array}{l}\text { Timely inspection by } \\
\text { authorized personnel }\end{array}$ & 3 & 33 & 4 \\
\hline 7. & $\begin{array}{l}\text { Relationship with } \\
\text { buyer and collector }\end{array}$ & 9 & 26 & 5 \\
\hline 8. & Other (if any) & - & - & - \\
\hline
\end{tabular}

\section{Conclusion}

Existing seed distribution channels fail to maintain uninterrupted supply and consistent prices of vegetable and fruit seeds across the country. The study was conducted in 12 districts out of 64 districts regarding different vegetable and fruit seed production and marketing systems. The additional expense for doing wholesale business is higher than retail business for both cases. Demand and supply situations of vegetable and fruit seed range from low to high. The wholesale market is bigger than the retail market for both vegetable and fruit seeds. For improvement of the seed marketing system, seed quality and price should be considered wisely. On the other hand, farmers mostly follow a mixed cropping pattern for vegetable and fruit seed production. The price of vegetable and fruit seeds is determined by different channels, but mainly middlemen and farmers' friends. The prices of seeds depend on seasonality and the types of seeds especially hybrid seeds are more expensive rather than normal seeds. The farmers are satisfied with the fair price they get from selling their seed. The collectors play a major role in the seed marketing system and seeds are mostly sold in the local market. Farmers get technical support services from government organizations and marketing support services from private organizations. From the study, it was observed that lack of timely monitoring of seed production by government organizations and leads to poor quality seeds. The study revealed the current status of the vegetable \& fruit seed farming and marketing system which should be improved according to the above findings to make a sustainable distribution system for fruit and vegetable seeds. Bangladesh has a limited production of quality vegetable and fruit seeds, and consumers can not benefit from it, as a result, sustainable agricultural production and seed supply cannot be achieved.

\section{Recommendations}

From the study, it may be recommended that high-yielding vegetable and fruit seed varieties should be available on a timely basis and at a reasonable price across the country. Demand and supply should be maintained to the optimum level so that the production and price of the seeds remains the same. Quality imported vegetable and fruit seeds should be subsidized by the government. The government should come forward to maintain the ideal distribution system of vegetable and fruit seeds. Technical services and marketing support from the different organizations should be available so that farmers and the retailers \& wholesalers become benefited. In addition to technical guidance, policies related to the marketing system should be implemented; such as price checking and seed quality certification. Government institutes should be proactive in monitoring vegetable and fruit seed production and marketing to ensure the quality and proper distribution to the beneficiaries.

\section{References}

[1] Divesh, K. (2015). Sustainability adoption through buyer supplier relationship across supply chain: A literature review and conceptual framework. Indian Institute of Technology Roorkee, India, 3(1), 110.

[2] FAO, (2017). Trends and challenges: The future of food and agriculture, $9(1), 180$.

[3] Hazra, P. (2008). Upgradation Of The Vegetable Production Scenario Of Bangladesh: Suggested Strategy. J. Agrofor. Environ, 2(2), 204.

[4] Iacob, C. (2010). Setting Fair Prices - Fundamental Principle of Sustainable Marketing. The Bucharest Academy of Economic Studies, Romania, 12(27), 115.

[5] Luthfa, L. R. (2004). Market-Led Initiatives For Seed Production And Product Processing In Bangladesh. Bangladesh Journal Of Political Economy, 20(1), 125.

[6] Lynamm, J. (2010). Plant Breeding And Seed Systems. FAO Report, FAO, Department Of Agricultural Extension, Rome. 
[7] Marchese, A. (2015). Transportation for Sustainability. An International Conference, Transportation Research Board, Washington, DC.

[8] MOA, (Ministry of Agriculture) (2015). The National Seed Policy; Ministry of Agriculture in Bangladesh: Dhaka, Bangladesh.

[9] Negasi, M. Y. (2016) Marketing System Analysis of vegetables and fruits in Amhara Regional State: survey Evidence from Raya Kobo and Harbu Woredas Ethiopian Journal of Economics, 14(2), 2.

[10] Negasi, M. Y. (2015). Marketing System Analysis of Vegetables and Fruits in Amhara Regional States: Survey Evidence from Raya Kobo and Harbu Woredas. Ethiopian Journal of Economics, 24(2), 23.

[11] Negi, S. (2015). Issues and Challenges in the Supply Chain of Fruits \& Vegetables Sector in India: A Review. International Journal of Managing Value and Supply Chains, 6(2), 48.

[12] OECD, (2001). Adoption of technologies for sustainable farming systems Wageningen workshop proceedings, 2(21), 149.

[13] Ray, S. (2001). Vegetable Seed Marketing System in Some Selected Areas of Bangladesh. Online Journal of Biological Sciences, 1(6), 525 .

[14] Shaheb, M. R. (2015, Challenges of Seed Potato (Solanum tuberosum L.) Production and Supply. A Scientific Journal of Krishi Foundation, 13(1), 182.

[15] Tomar, B. S. (2011). Seed production: An entrepreneurial venture. Seed Production Unit, Division of Seed Science and Technology, IARI, New Delhi, 4(61), 5 .

[16] Tripp, R. (200o). Strategies for seed system development in subSaharan Africa: a study of Kenya, Malawi, Zambia and Zimbabwe. Working paper series no. 2, Bulawayo, Zimbabwe, London: ICRISAT, ODI.

[17] Vriend, H. (2009). Towards sustainable development of deltas: Aquaterra research on trends and responses, 1 (17), 39. 